\title{
Structural Glass Fiber Reinforced Concrete for Slabs on Ground
}

\author{
Philipp Löber, Klaus Holschemacher \\ University of Applied Sciences, Institute of Concrete Construction, Leipzig, Germany \\ Email: philipp.loeber@htwk-leipzig.de
}

Received July 2014

\begin{abstract}
This paper aims to contribute to the classification and specification of glass fiber reinforced concrete (GFRC) and to deal with the question if structural glass fiber reinforced concrete as a special kind of glass fiber reinforced concrete is suited for use in load-bearing members. Despite excellent material properties, the use of glass fibers in a concrete matrix is carried out so far only in nonstructural elements or as a modification for the prevention of shrinkage cracks. The aim of research at the University of Applied Sciences in Leipzig is the use of alkali-resistant macro glass fibers as concrete reinforcement in structural elements as an alternative to steel fiber reinforcement. Slabs on ground, as an example for structural members, provide a sensible application for the new material because they can be casted as load bearing and non-load bearing and are mostly made of steel fiber reinforced concrete. In the future, structural glass fiber reinforced concrete shall provide a simple and visually appealing alternative to conventional steel bar or steel fiber reinforced concrete. The glass fibers can also be used in combination with conventional reinforcing bars or mat reinforcements. Initial investigations have announced some potential.
\end{abstract}

\section{Keywords}

Glass Fiber Reinforced Concrete, GFRC, Slab on Ground, Structural Concrete, Bending Test

\section{Introduction}

Approximately 25\% of all industrial floors were made of steel fiber reinforced concrete [3]. Hence, steel fibers have been successfully used for foundations such as slabs on ground for years. They made their way into several other fields of civil engineering such as tunnel or bridge construction. So far, the use of glass fibers as reinforcement material for load-bearing concrete structures has failed because there are no suitable fibers for normal concretes, which are able to transmit forces reliable, durable and can be mixed economically in large quantities. An ongoing research project at the University of Applied Sciences is intended to examine whether special macroglass fibers can be introduced reliably in vibrated concrete and are as composite material suited for the use in structural members especially slabs on ground.

\section{State of the Art}

Due to the use of glass fibers in a concrete matrix a lot of properties such as crack distribution and crack devel- 
opment in the concrete can be improved. Glass fibers are able to improve the flexural strength due to their high tensile strength of $1.700-3.700 \mathrm{~N} / \mathrm{mm}^{2}$ and their good bond with the cement matrix. However, this effect appears only at very high fiber contents from 3\% - 5\% of concrete volume [5]. In these ratios the fibers cannot anymore mixed in the concrete because of the loss of consistency and bad fiber distribution. Due to their relatively low stiffness compared to steel fibers, glass fibers are able to bridge very small cracks and to support the concrete already during setting (flow of hydration heat and shrinkage) and contribute to its impermeability. Concrete covers as well as minimal cement contents must not be ensured. Therefore GFRC is used for thin elements or for repair of existing components. Examples for usage are prefabricated elements in façade construction, noise barriers, place formwork, fire-resistant panels, design elements in the interior or for the renovation of old floors as glass fiber modified concrete [1]. In Germany there are a few standards dealing with test methods for glass fiber reinforced concrete [9]. These standards are used for testing thin panels of traditional glass fiber reinforced concrete with high fiber concrete. For structural use of GFRC no rules exist. At the moment slabs on ground are constructed with reinforcement bars, steel fiber reinforced concrete, with combined reinforcement (bars and steel fibers) or are made pre-stressed. If slabs on ground may also be constructed with structural GFRC, has still to be investigated.

\section{Structural Glass Fiber Reinforced Concrete-Conceptual Alignment}

The term glass fiber reinforced concrete is often used in civil engineering representative of a whole group of composite building materials and has to be differentiated with respect to material behavior [5]. A distinction is made between [3]:

- textile reinforced concrete (use of glass fiber rovings (continuous fibers) as reinforcement, analogous to bar or mat reinforcement);

- glass fiber modified concrete (using microfibers of 12 - 30 mm length, produced in mixing, good for prevention of shrinkage cracks in concrete applications, fiber content up to 1 vol\%) and;

- (traditional) glass fiber reinforced (fine) concrete or mortar (using macro fibers up to $50 \mathrm{~mm}$ length in spraying method for very thin GFRC applications, fiber content up to 5 vol\%).

Structural glass fiber reinforced concrete shall be the fourth kind of GFRC wherein the fibers, similar to glass fiber modified concrete in the form of short macrofibers are mixed with a three-dimensional arrangement in the concrete matrix. Due to excellent mechanical properties, glass fibers (see Table 1) can be used as reinforcing material in the concrete. However, as usual they have to have a high durability in typical concrete alkaline environment. Therefore only alkali resistant fibers are suited.

In structural GFRC integral AR-macro glass fibers with a length of $36 \mathrm{~mm}$ and a slenderness of 67 are used. As matrix, normal vibrated concrete with a maximum grain size of $16 \mathrm{~mm}$ was used in former tests. Structural GFRC should be economical and easy to prepare, that is why it has to be produced in mixing process and shall be transported via pump to the respective point of use. That is the reason why the fibers can be interfered only in small amounts in the mixing process due to their length. Approximately fiber contents up to $15 \mathrm{~kg} / \mathrm{m}^{3}$ are possible with this kind of production. Glass fibers react sensitive and brittle at transverse pressure. This is due to their low stiffness and the composition of individual filaments. Therefore, it is important to restrict the mechanical impacts during mixing to a minimum. In structural glass fiber reinforced concrete, the fibers are not used to increase the tensile strength of the composite building material, but to make the concrete more ductile and give it a post cracking tensile strength as it is known from steel fiber reinforced concrete with a strain-softening material behavior after concrete cracking. This shall be sufficient for use in statically highly indeterminate structures like slabs on ground. In these members structural GFRC can represent a visually appealing alternative to steel fiber reinforced concrete. It is resistant to corrosion and can normally be used without surface protection system also because fibers coming out of the surface are harmless.

\section{Investigations}

At the University of Applied Sciences, Leipzig, four test series with 14 specimens each were carried out. The mix design was done on experiences with steel fiber reinforced concrete (see Table 2). The four series contain two different fiber contents ( 5 and $7 \mathrm{~kg} / \mathrm{m}^{3}$ ) each with two different mixing times (45 and $180 \mathrm{sec}$ ) after addition of fibers. Seven specimens of each series were tested in three- and four-point bending tests according to German [2] and European [6] regulations, respectively. The number of specimens has to be at least six [2] on the basis of 
Table 1. Mechanical properties of different fiber materials [8].

\begin{tabular}{ccccc}
\hline \multirow{2}{*}{ Property } & \multicolumn{3}{c}{ Materials } \\
\cline { 2 - 5 } & AR-Glass & Steel & PVA (plastic) & Carbon fiber \\
\hline Density, g/cm & & 7.85 & 1.30 & 1.80 \\
Tensile strength, N/mm & 2.68 & $1000-2600$ & $880-1600$ & $3000-5000$ \\
Modulus of elasticity, $\mathrm{N} / \mathrm{mm}^{2}$ & $1500-3700$ & $\sim 200,000$ & $\sim 30,000$ & $\sim 230,000$ \\
Ultimate strain, \% & 72,000 & $2.5-10$ & $\sim 8$ & 1.50 \\
\hline
\end{tabular}

a. Tensile strengths vary depending on the fiber material composition and the type of sample the test was carried out. Tensile strengths of fiber filaments are much higher compared with fiberbundles such as strands or rovings.

Table 2. Used GFRC mixtures.

\begin{tabular}{|c|c|c|c|c|}
\hline \multirow{2}{*}{ Ingredients } & \multicolumn{4}{|c|}{ Series } \\
\hline & I (5 - 180) & II $(7$ - 180) & III (5 - 45) & IV $(7-45)$ \\
\hline Sand $0 / 2, \mathrm{~kg} / \mathrm{m}^{3}$ & 732 & 731 & 727 & 726 \\
\hline Gravel 2/8, kg/m ${ }^{3}$ & 465 & 465 & 462 & 462 \\
\hline Gravel 8/16, kg/m³ & 670 & 670 & 666 & 665 \\
\hline CEM I $42.5 \mathrm{R}, \mathrm{kg} / \mathrm{m}^{3}$ & 300 & 300 & 300 & 300 \\
\hline Water, $1 / \mathrm{m}^{3}$ & 180 & 180 & 185 & 185 \\
\hline Superplasticizer, \% & 0.75 & 1 & 1 & 1 \\
\hline Water/Cement & 0.6 & 0.6 & 0.62 & 0.62 \\
\hline Fibercontent kg/m³ & 5 & 7 & 5 & 7 \\
\hline Mixing time, sec & 180 & 180 & 45 & 45 \\
\hline
\end{tabular}

statistical reasons. Table 2 shows the investigated versions.

\subsection{Materials}

The matrix used for the glass fibers was a normal weight, vibrated concrete (C25/30) with a maximum grain size of $16 \mathrm{~mm}$ and a grading curve A/B 16. As additives only superplasticiser “Muraplast FK 43” was used to achieve a flowable consistency (F3 or higher, [7]). The fibers used were integral AR-macro glass fibers with a length of $36 \mathrm{~mm}$ and a slenderness of 67 . Cement and aggregates were first placed in a pan forced mixer and mixed for $30 \mathrm{~s}$. Water was then added, followed by flow agent, and finally the fibers. The mixing times of $180 \mathrm{~s}$ and $45 \mathrm{~s}$ are related to the time after the addition of glass fibers. The mixtures used are listed in Table 2. The slump in each case was around F3 and the air content at around 3.5\%. For hardened concretes properties the compressive strength, splitting tensile strength and the residual flexural strength according to German and European regulations were measured. The aim was to achieve a C25/30 which was given with an average compressive strength of $36 \mathrm{~N} / \mathrm{mm}^{2}$.

\subsection{Bending Tests}

Normally, the flexural bearing capacity of glass fiber reinforced concrete according to [4] is determined on thin plate stripes in four-point bending tests. However, the tests described are based on glass fiber reinforced fine concrete or mortar. As part of the research program at the University of Applied Sciences, Leipzig, it was decided to perform these tests in accordance with the guidelines for steel fiber reinforced concrete [2] and [6]. A total of 56 fiber concrete beams have been tested on their structural behavior, especially after the first peak. With a defined speed the deformation fields 1 and 2 were covered and recorded the load-deflection or loadCMOD curves. These are used to determine the residual tensile strengths and the performance classes according to [2]. The tests differ in the definition of the deformation fields for the SLS and ULS, specimen geometry, loading rate and evaluation of results. 


\subsubsection{German Regulation "DAfStb Guideline for Steel Fiber Reinforced Concrete"}

The investigation in accordance to the German guideline from the German Committee for Reinforced Concrete Structures (DAfStb) is done with fiber concrete beams with dimensions of $70 \times 15 \times 15 \mathrm{~cm}$. The clear span is 60 $\mathrm{cm}$ and the displacement-controlled loading is done in the third points (see Figure 1).

Deformation field 1 stands for the SLS and describes a deflection of $0.5 \mathrm{~mm}$ at midspan. Up to $0.75 \mathrm{~mm}$ the loading speed is $0.1 \mathrm{~mm} / \mathrm{min}$ and afterwards up to $0.3 \mathrm{~mm} / \mathrm{min}$. Deformation field 2 (ULS) ends at $3.5 \mathrm{~mm}$ deflection. The average load-deflection curves of all specimens are shown in Figure 2.

Steel fiber reinforced concrete in Germany is divided in the so-called performance classes. These classes describe the residual strengths for defined deflections of the composite material and are needed for the design process. Therefore the characteristic value of the residual flexural strength for the two deformation fields is determined. The average value of the residual flexural strength of at least $n=6$ beams is given by:

$$
f_{c f l m, L 1}^{f}=\frac{1}{n} \sum_{i=1}^{n} \frac{F_{0.5, i} \cdot l}{b_{i} \cdot h_{i}^{2}}
$$

For deformation field $2 \mathrm{~F}_{3,5}$ has to be used instead of $\mathrm{F}_{0,5} . \mathrm{F}_{0,5}$ and $\mathrm{F}_{3,5}$ are the forces corresponding to deflections of 0.5 and $3.5 \mathrm{~mm}$.

The chars l, b und h stand for the length, wide and height of the specimen. The characteristic value of the residual flexural strength is then calculated with:

$$
f_{c f l k, L i}^{f}=e^{\left(L f_{c f m l, L i}^{f}-k_{s} \cdot L s\right)} \leq 0.51 \cdot f_{c f l m, L i}^{f}
$$

where

$L f_{\mathrm{cfml}, \mathrm{Li}}^{\mathrm{fi}}$ is the average value of the logarithmized single test values $f_{\mathrm{cfl}, \mathrm{Li}, \mathrm{I}}^{\mathrm{f}}$ with

$$
L f_{c f m l, L i}^{f}=1 / n \cdot \sum \ln \left(f_{c f l, L i, i}^{f}\right),
$$

$L s$ is the standart deviation of the logarithmized single test values of the series with

$$
L s=\sqrt{\frac{\sum\left(L f_{c f l m, L i}^{f}-\ln \left(f_{c f l, L i, i}^{f}\right)\right)^{2}}{n-1}}
$$

and $k_{\mathrm{s}}$ the fractile factor for unknown standart deviation for the $5 \%$-quantile with $75 \%$ propability. If six specimens are taken, $k_{\mathrm{s}}$ is 2336. The corresponding strengths are given in Figure 3.

\subsubsection{European Regulation "EN 14651 or RILEM TC $162-$ TDF"}

The tests in accordance with EN 14651 are done with fiber concrete beams with dimensions of $55 \times 15 \times 15 \mathrm{~cm}$ and up to $5 \mathrm{~mm}$ wide notch at the bottom in the middle. The clear span is $50 \mathrm{~cm}$ and the displacement-controlled loading is applied at midspan (see Figure 4). In comparison to the four-point bending test not the deflection, but the CMOD (crack mouth opening displacement) is taken into evaluation. Alternatively, if not measured, CMOD can be calculated linearly out of the deflection.

The deformation field 1 is up to a CMOD of $0.5 \mathrm{~mm}$. The loading rate is $0.05 \mathrm{~mm} / \mathrm{min}$ until $0.1 \mathrm{~mm}$ deflection. From this point, the loading rate can be increased to $0.2 \mathrm{~mm} / \mathrm{min}$. The deformation field 2 ends at $2.5 \mathrm{~mm}$. In addition, the test should be continued up to a crack opening of $4 \mathrm{~mm}$. Figure 5 shows the load-crack opening curve of the mean value curves of all test series.

The residual flexural strength $f_{R, j}$ according to [6] is determined as follows:

$$
f_{R, j}=\frac{3 F_{j} l}{2 b h_{s p}^{2}}
$$

For the calculation of the limit of proportionality (LOP) $f_{c t, L}^{f}$ insert $F_{L}$ instead of $F_{j}$. The corresponding strengths are shown in Figure 6.

\subsection{Evaluation}

The evaluation showed, that the concrete in region 2 (ultimate limit state) has insufficient load bearing capacity to substitute normal reinforcement. In region 1 (limit state of serviceability), however, the Series II (7 - 180) 


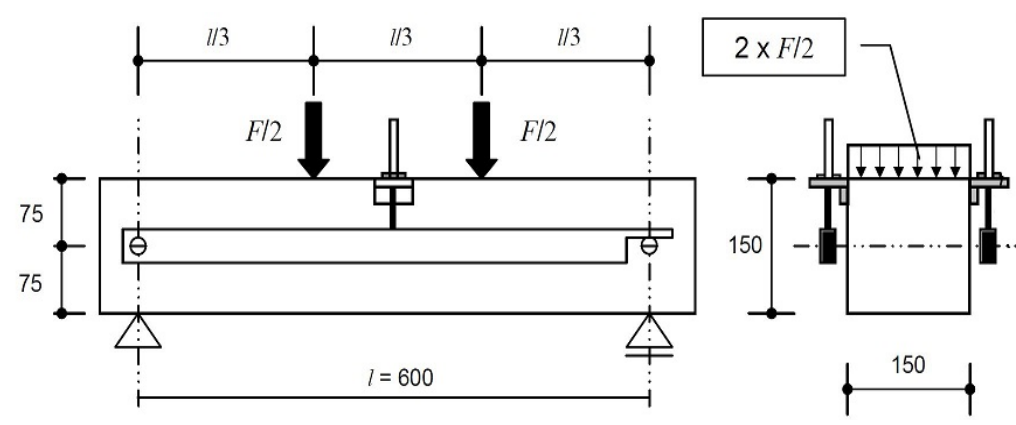

Figure 1. Experimental setup: four-point bending test according to German guideline [2].

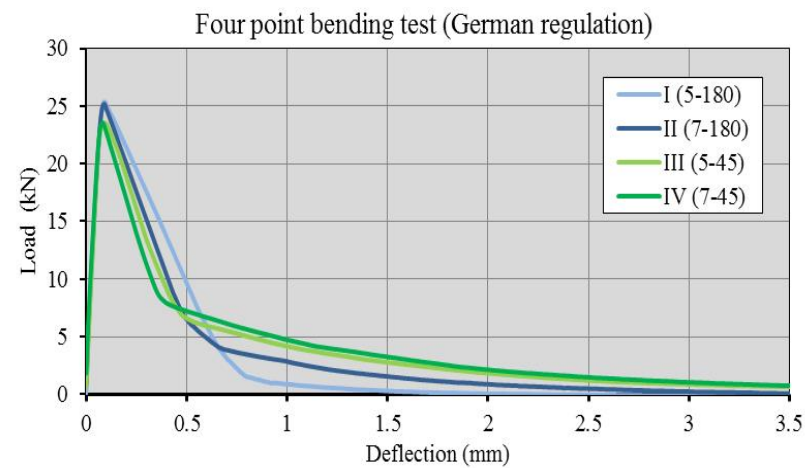

Figure 2. Average load-displacement curves of the four-point bending tests.

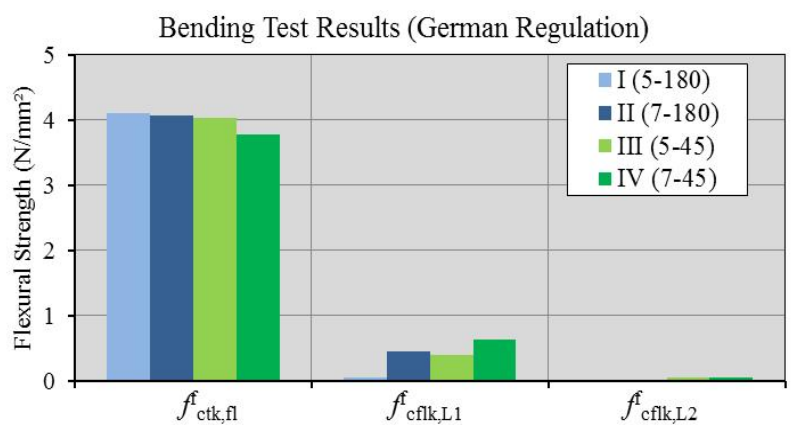

Figure 3. Characteristic flexural strength values according to [2].
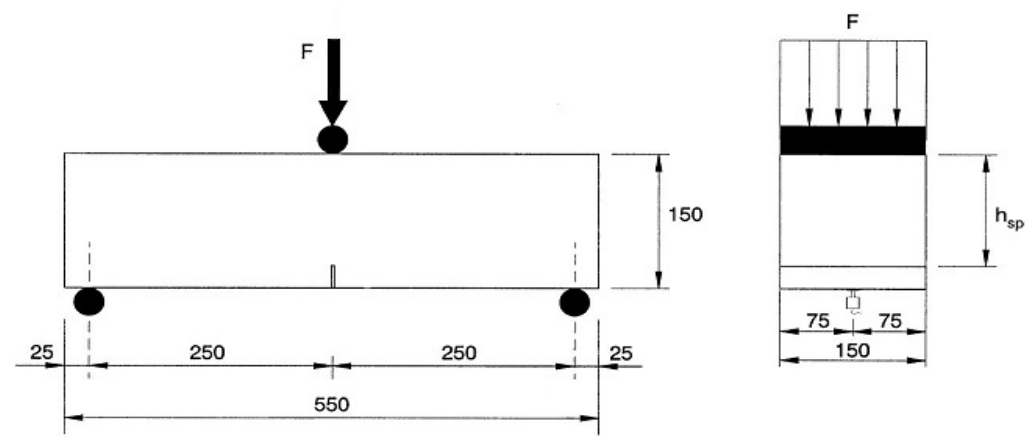

Figure 4. Experimental setup: three-point bending test according to RILEM guideline [6]. 


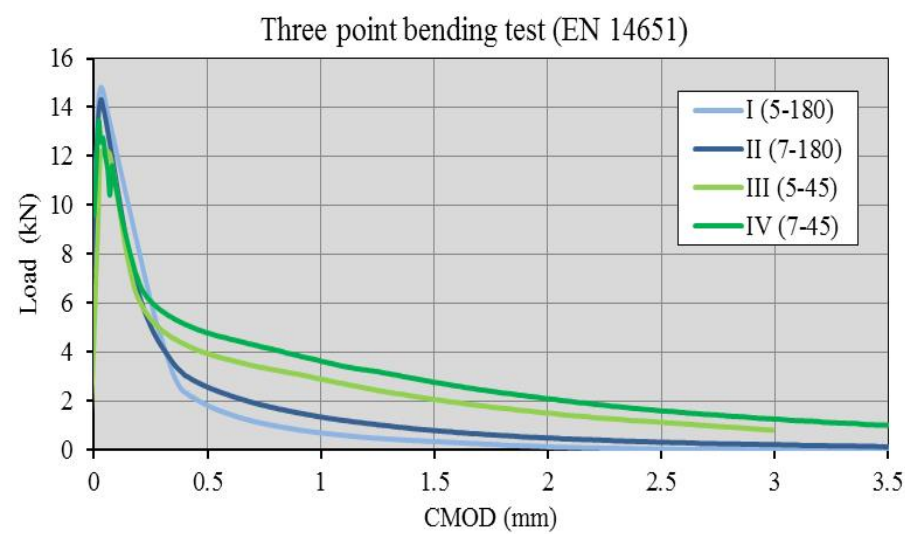

Figure 5. Average load-displacement curves of the three-point bending tests.

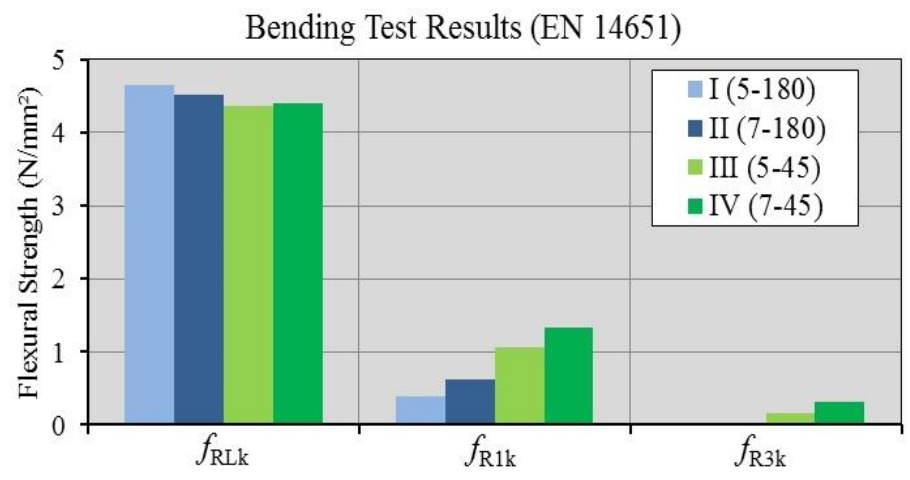

Figure 6. Characteristic flexural strength values according to [6].

with performance class $0.4 / 0$ and IV ( 7 - 45) with performance class $0.6 / 0$ announced some potential. The German guideline allows the use of this fiber concrete for plane members (width $>5$ times height).

Similar conclusions occurred after evaluation according to EN 14651. The influence of mixing time after addition of fibers on the load bearing capacity was quite significant. Using wash out tests it was found, that the fiber damage is obviously increased with increasing mixing time. This statement was confirmed in the evaluation of the load-displacement curves. In both diagrams, an increase of loading capacity after first crack can be seen when using higher fiber contents. The influence of mixing time on the residual strengths is even more significant. Whereas a $40 \%$ increase of fiber content results in a $59 \%$ increase of flexural strengths, an increase of $144 \%$ could be obtained by reduction of the mixing time to a quarter with the same fiber content. The influence of mixing time on the residual tensile strength decreases with increasing fiber content, but plays an important role in the production of load-bearing parts consisting of glass fiber reinforced concrete. A minimum mixing time, however, with regard to a uniform fiber distribution has to be ensured. Therefore balance between a uniform fiber distribution and a minimal fiber damage degree by the mixing process has to be found.

\section{Conclusion}

The focus of research at the University of Applied Sciences, Leipzig is the design of a glass fiber reinforced concrete for structural components and the study of the suitability of this concrete in slabs on ground. The mentioned tests were all carried out with normal concrete as the matrix. Further tests should show whether a performance gain can be achieved with a different concrete mixture as well as other fiber contents and mixing times. At the moment it is still difficult to detect the failure mechanism of the individual fibers. The goal is a failure by fiber pull-out, to have ductile failure of the member. However, it turns out that it is difficult to detect and determine whether a glass fiber is broken or pulled out of the matrix. The reason is the very slight color difference from the matrix and the fact that the fiber surface after testing appears very worn. 


\section{References}

[1] Fachvereinigung Faserbetone e.V. (2013) http://www.fvf-faserbeton.de/

[2] Deutscher Ausschuss für Stahlbeton (DAfStb) (2010) Richtlinie “Stahlfaserbeton”. Ergänzung zu DIN 1045, März 2010.

[3] Falkner, H. and Teutsch, M. (2006) Stahlfaserbeton-Anwendungen und Richtlinie. In: Betonkalender, Ernst \& Sohn Verlag, Berlin, 667-703.

[4] (1998) DIN EN 1170-5 Precast Concrete Products—Test Method for Glass-Fibre Reinforced Cement-Part 5: Measuring Bending Strength. Complete Bending Test Method, German Version.

[5] Schorn, H. (2010) Fiber Reinforced Concretes for Load Bearing Structures. (German) Verlag Bau + Technik GmbH, Düsseldorf.

[6] (2007) EN 14651:2005 + A1:2007 Test Method for Metallic Fibre Concrete-Measuring the Flexural Tensile Strength (Limit or Proportionality (LOP), Residual), German Version.

[7] (2009) EN 12350-5:2009: Testing Fresh Concrete-Part 5: Flow Table Test, German Version.

[8] Holschemacher, K., Klug, Y. and Dehn, F. (2011) Grundlagen des Faserbetons. In: Betonkalender 2011, Ernst \& Sohn Verlag, Berlin, 21-88.

[9] (1998) DIN EN 1170 Precast Concrete Products-Test Method for Glass-Fibre Reinforced Cement. 